\title{
GLUEPS-AR: A System for the Orchestration of Learning Situations Across Spaces Using Augmented Reality
}

\author{
Juan A. Muñoz-Cristóbal, Luis P. Prieto, Juan I. Asensio-Pérez, Iván M. Jorrín- \\ Abellán, Alejandra Martínez-Monés, Yannis Dimitriadis \\ GSIC-EMIC Group, Universidad de Valladolid, Spain \\ juanmunoz@gsic.uva.es, lprisan@gsic.uva.es, juaase@tel.uva.es, \\ ivanjo@pdg.uva.es, amartine@infor.uva.es, yannis@tel.uva.es
}

\begin{abstract}
Ubiquitous and mobile learning scenarios define activities happening within and beyond the walls of a classroom. However, the orchestration of authentic learning situations involving both physical and virtual spaces is still a significant challenge for teachers. Several proposals recently reported in the literature try to reduce teachers' orchestration burden by means of authoring tools, and usage of Augmented Reality technologies for connecting physical and virtual spaces. However, these proposals are restricted to specific technologies, pedagogies, or to a very limited range of activities. We present GLUEPS-AR, a system to aid teachers in the orchestration of across-spaces learning situations. With GLUEPS-AR, learning designs defined with multiple authoring tools can be deployed and managed at run-time throughout ubiquitous learning environments composed by different VLEs, Web 2.0 tools and AR applications. Thus, GLUEPS-AR allows multiple design and enactment technologies, and a wide range of learning activities, not restricted to a single pedagogy.
\end{abstract}

Keywords: Augmented reality, across spaces, ubiquitous learning, VLE, orchestration

\section{Background (Pedagogy)}

Different pedagogical approaches explore learning beyond the traditional classroom, such as ubiquitous, situated or place-based learning. A fundamental issue in these ubiquitous contexts is to maintain a continuous learning experience across the different spaces where learning occurs [1]. This is especially challenging in collaborative scenarios, which pose still more technology and pedagogical difficulties. Augmented reality (AR) is a technology that may be used to connect physical and virtual spaces, as AR is based on the superposition of virtual objects in physical environments [2]. AR has also pedagogical affordances, such as the capability of enhancing spatial skills using $3 \mathrm{D}$ virtual objects, the potential positive impact on the engagement of students, and the scaffolding in learning (e.g., guiding students with AR). 


\section{Background (Technology)}

Existing research work provides a variety of solutions for the deployment of acrossspaces learning situations using AR to connect physical and virtual spaces. Interestingly, these initiatives typically use learning design processes to facilitate teachers' deployments, in the form of authoring tools [3,4]. Learning design [5] is a field of research in technology enhanced learning, based in the explicit formulation by practitioners of their pedagogical ideas, which are often defined in a computational form.

However, the existing across-spaces prototypes have limitations that may complicate their adoption by teachers: a) these prototypes work with a limited range of authoring and enactment tools (usually, only one of each type); b) some of these prototypes are also oriented to specific pedagogies (e.g., game based learning); and c) they are usually restricted to a particular kind of learning activities (e.g., activities consisting on a sequence of pre-specified AR artifacts). However, teachers need more flexible approaches, able to accommodate to the technologies and pedagogies that they already use in their daily practice.

\section{$3 \quad$ Results and Outcomes Achieved}

We propose GLUEPS-AR [6] to aid teachers in the orchestration of across-spaces learning situations. GLUEPS-AR is a system for the deployment of learning designs (which may be defined using multiple authoring tools) into multiple ubiquitous learning environments. Such ubiquitous environments are composed by Virtual Learning Environments (VLE), AR-enabled physical spaces, and Web 2.0 tools. GLUEPS-AR also allows the run-time management of such learning situations.

We have defined a technological architecture that extends a predecessor system centered on distributed Web spaces called GLUE!-PS ${ }^{1}$. The architecture is based on a number of adapters that enable the integration of authoring tools (e.g., WebCollage ${ }^{2}$ or Pedagogical Pattern Collector ${ }^{3}$ ), VLEs (e.g., Moodle ${ }^{4}$ ), AR applications (e.g., QR code readers or Junaio ${ }^{5}$ ) and Web 2.0 tools (using multi-tool managers, such as GLUE! ${ }^{6}$ or IMS-LTI ${ }^{7}$ to integrate multiple external tools in VLEs).

By means of these adapters, Web 2.0 tools and other virtual artifacts (e.g., 3D models) may be accessed from both VLEs and physical spaces, in a global acrossspaces learning situation. Virtual learning artifacts may be positioned in physical spaces through AR with different positioning types (e.g., QR codes, visual markers or geo-position). As GLUEPS-AR is not restricted to a reduced number of design or enactment technologies, it may support multiple pedagogies and activity types.

\footnotetext{
${ }^{1}$ https://www.gsic.uva.es/glueps/. Last access, April 2013.

${ }^{2}$ http://pandora.tel.uva.es/wic2/. Last access, April 2013.

${ }^{3}$ http://thor.dcs.bbk.ac.uk/projects/LDSE/Dejan/ODC/ODC.html. Last access, April 2013.

${ }^{4}$ http://moodle.org. Last access, April 2013.

${ }^{5}$ http://www.junaio.com. Last access, April 2013

${ }^{6}$ https://www.gsic.uva.es/glue/. Last access, April 2013.

${ }^{7}$ http://www.imsglobal.org/toolsinteroperability2.cfm. Last access, April 2013.
} 
A prototype has been developed to illustrate the architecture and test it. Fig. 1 shows GLUEPS-AR's architecture and user interface. The interface allows to modify, complete and configure the initial design (e.g., including concrete participants/groups, adding tool configurations, etc.). The Figure also displays the different authoring tools and learning environments (VLEs and AR applications) supported by the prototype. We have accomplished an initial evaluation, co-designing a complex across-spaces situation with a faculty member of the College of Education at the Universidad de Valladolid (Spain). The teacher co-deployed the learning situation using GLUEPSAR and simulated part of the enactment, giving positive feedback about the deployment process and the possibilities of the approach. This learning situation, as well as others currently being designed, are planned to be realized with actual students in the upcoming academic year.

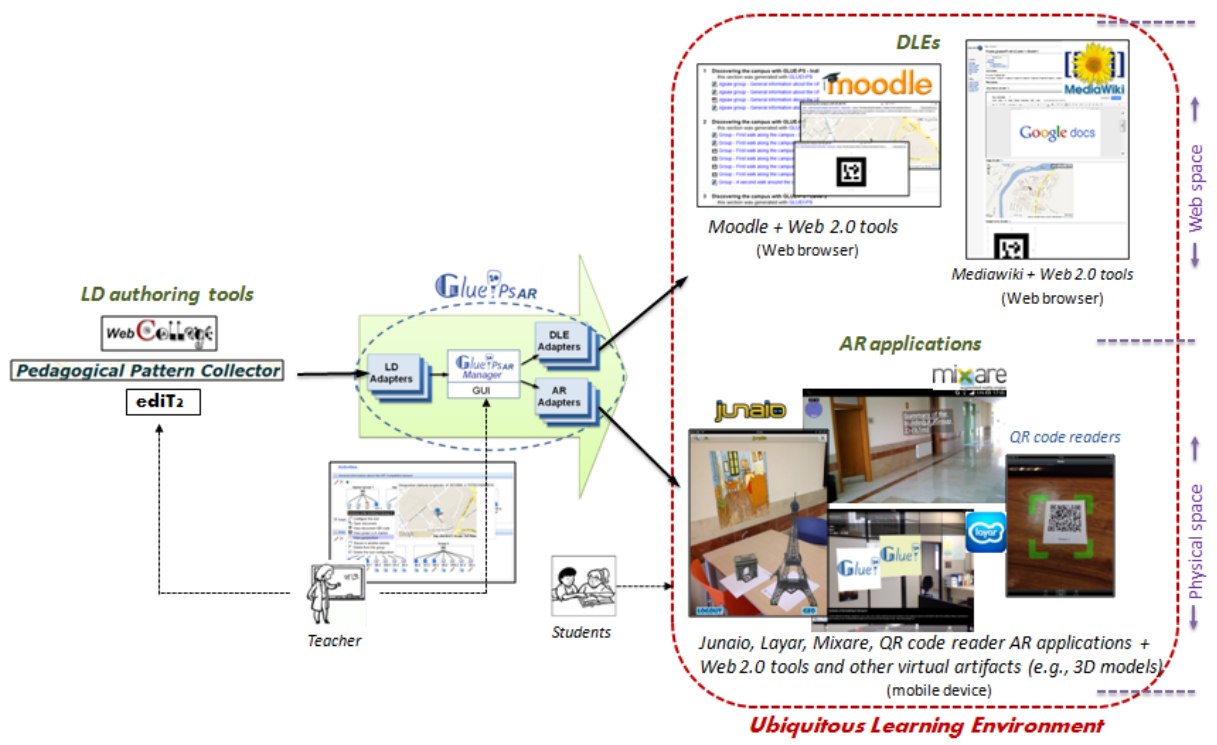

Fig. 1. GLUEPS-AR architecture (center), and design and enactment tools currently supported by the prototype (left and right, respectively).

\section{Demonstration Outline}

The demonstration will show how an initial across-spaces learning design (that has been previously defined in an authoring tool, such as WebCollage) can be deployed in minutes into a ubiquitous learning environment composed by a VLE, Web 2.0 tools (Web space), and an AR application (physical space). The setting up of the learning design ready for enactment in the ubiquitous learning environment can be verified with computers and mobile devices (tablet and smartphones) simulating how students would access the learning artifacts available in different spaces during enactment. 


\section{$5 \quad$ Specific Technology and Environment Needed at Conference}

Demonstration will be performed by 1-2 demonstrators. A good wireless (Wifi) Internet connection is required, so that mobile devices can download AR objects to be rendered. We will use laptops, tablets and smartphones (provided by us). We would need a projector and VGA cable (to connect projector and laptop), and a surface for projection (an alternative to the projector could be a PC monitor with at least 21'). If there is a demonstration session where people cannot be close to our laptop and mobile devices, (e.g., a plenary session with a sequence of demonstrations towards a sat audience), we would need two projectors (in order to project simultaneously laptop and tablet screens), and two VGA cables.

\section{Acknowledgements}

This research has been partially funded by the Spanish Projects TIN2011-28308-C0302 and VA293A11-2, and the European Project 531262-LLP-2012-ES-KA3-KA3MP. The authors thank as well the rest of the GSIC/EMIC research team.

\section{References}

1. Sharples, M., Sanchez, I.A., Milrad, M., Vavoula, G.: Mobile learning: small devices, big issues. In: Balacheff, N., Ludvigsen, S., de Jong, T., Barnes, S. (eds.) Technology Enhanced Learning: Principles and Products. pp. 233-249. Springer, Heidelberg, Germany (2009)

2. Azuma, R., Baillot, Y., Behringer, R., Feiner, S., Julier, S., MacIntyre, B.: Recent advances in augmented reality. Computer Graphics and Applications, IEEE 21(6), 34-47 (2001).

3. Klopfer, E., Sheldon, J., Perry, J., Rosenheck, L., Squire, K., Mathews, J., Shapiro, R.B., Coulter, B., Dunleavy, M.: Augmented reality games: place-based digital learning. In: Proceedings of the 9th International CSCL Conference, Hong Kong, China, July 2011

4. Santos, P., Pérez-Sanagustín, M., Hernández-Leo, D., Blat, J.: QuesTInSitu: From tests to routes for assessment in situ activities. Computers \& Education 57(4), 2517 - 2534 (2011).

5. Koper, R.: An Introduction to Learning Design. In: Koper, R., Tattersall, C. (eds.) Learning Design modelling and implementing networkbased education training, vol. 2003. pp. 3-20. Springer, (2005)

6. Muñoz-Cristóbal, J.A., Prieto, L.P., Asensio-Pérez, J.I., Jorrín-Abellán, I.M., Dimitriadis, Y.: Orchestrating TEL situations across spaces using Augmented Reality through GLUE!PS AR. Bulletin of the Technical Committee on Learning Technology 14(4), 14-16 (2012). 